The Labore Journal of Economics

$11: 2$ (Winter 2006) pp. 23-41

\title{
Technical Efficiency of Some Selected Manufacturing Industries in Bangladesh: A Stochastic Frontier Analysis
}

\author{
Md. Azizul Baten", Masud Rana ${ }^{*}$, Sumonkanti Das" and \\ Md. Abdul Khaleque
}

\section{Abstract}

This paper investigates the technical efficiency of selected manufacturing industries of Bangladesh using a stochastic frontier production function approach suggested by Battese and Coelli (1992) applied to panel data. A feasible Cobb-Douglas stochastic frontier production function, which has time-varying technical inefficiency effects, was estimated. Two alternative distributions were used to model the random inefficiency term: a truncated normal distribution and a halfnormal distribution. The estimated average technical efficiency for four groups of industries of Bangladesh over the reference period was $40.22 \%$ of potential output for the truncated normal distribution, whereas it was $55.57 \%$ of potential output for the half-normal distribution.

Keywords: Stochastic frontier, Production function, Technical efficiency

\section{Introduction}

One of the most important and fascinating aspects of economic change in Bangladesh in the last three decades has been the growth of manufacturing. There is great scope for the manufacturing sector of Bangladesh to improve its technical efficiency; without improving its technical efficiency, the sector cannot play the desired role in the process of economic development of the country. The manufacturing process may play a vital role in the development process by creating new jobs, increasing exports, and displacing imports. But efficiency is the first condition that has

\footnotetext{
* Department of Statistics, Shah Jalal University of Science and Technology, Sylhet3114, Bangladesh.

** Department of Statistics and Computer, Dhaka Commerce College, Dhaka, Bangladesh.
} 
to be achieved to be competitive internationally. In order to accelerate the development process, industries have to be come technically efficient.

Following the seminal paper by Farrell (1957), frontier production functions were introduced and have been widely applied by different researchers. The stochastic frontier production function was independently proposed by Aigner, Lovell and Schmidt (1977), Meeusen and van don Broeck (1977) and Battese and Corra (1977), and there have been a vast range of applications in the literature. (For literature surveys see Greene (1993) and Rao and Coelli (1998)). The model was originally defined for the analysis of cross-sectional data but various models to account for panel data have been introduced by Pitt and Lee (1981), Cornwell, Schmidt and Sickles (1990), Kumbhakar (1990), Kumbhakar, Ghosh and Mcgukin (1991). Battese, Malik and Broca (1993) and Battese. Malik and Gill (1996) studied the frontier production function, considering four years of panel data for each of four districts of Pakistan and a modified Cobb-Douglas production frontier in which the models for the technical inefficiency effects were specified by Battese and Coelli (1992,1995). Battese and Coelli (1995) proposed a stochastic frontier production frontier for panel data, which has firm effects assumed to be distributed as truncated normal random variables, which are also permitted to vary systematically with time and in which the inefficiency effects are directly influenced by the number of variables. By using the same model, Taymaz and Saatci (1997) estimated the stochastic production frontier for Turkish textile, cement and motor vehicle industries. A frontier production function studied by Ajibefun, Battese and Kada (1996) applyied time-varying inefficiency model using eleven years of data on rice production in prefectures in Japan. They suggested that the traditional average response function, which does not account for the technical inefficiency of production, is not an adequate representation of the data. Tzouvelekas et. al. (1999) investigated the relative contribution of technical efficiency, technological change and increased input use to the output growth of the Greek olive-oil sector using a stochastic frontier production function approach applied to panel data. Jafrullah (1996) studied the technical efficiency of 19 four-digit manufacturing industries of Bangladesh and concluded that the manufacturing industries of Bangladesh analyzed were not highly technical but efficient.

In fact, few studies have been done to see the technical efficiency of Bangladeshi manufacturing industries using panel data. Future, efficiency has seldom been studied for manufacturing industries in Bangladesh using the stochastic frontier production function [Jafrullah M, (1996)]. Since estimation of the production function by standard panel analysis does not 
present information such as efficiency in the production function, we analyze the stochastic frontier production function in this study.

The objective of this study is to apply the stochastic frontier production function to investigate the technical efficiencies of four threedigit level industries of Bangladesh for panel data. This study is important in predicting the technical efficiencies for the selected group of manufacturing industries, but also indicates the trend of efficiency over the period, $1981 / 82$ - 1999/2000. At the same time, it is desirable to see whether technical efficiency is time varying or time invariant. The paper proceeds as follows: the next section reviews the stochastic frontier production function approach to modeling inefficiency. This includes a discussion of the determinants of inefficiency used here. The data is discussed in section 3, while section 4 provides and discusses the results from estimating the stochastic production frontier. Finally, the last section presents conclusions.

\section{Stochastic Frontier Model with Technical Efficiency Effects}

In this study we have considered the Stochastic Frontier Model to measure the technical efficiency of selected manufacturing industries in Bangladesh. The framework assumes the existence of a best practice frontier corresponding to fully efficient operation in the industry under investigation. This frontier defines the maximum level of output that can be obtained from any vector of resource inputs in the absence of uncertainty. The stochastic component of the frontier consists of two types of disturbance or error terms. The first is a regular symmetric disturbance that represents statistical noise in a typical regression. The second disturbance or error term, which is firm specific, is a one-sided deviation from this idealized frontier, and is referred to as technical inefficiency. The greater the amount by which the realized production falls short of the stochastic frontier, the greater the level of technical inefficiency.

The measurement of technical inefficiency has received renewed attention since the late eighties from an increasing number of researchers, as the frontier approaches to efficiency measurement have become more popular. The introduction of the frontier approach has raised the level of analysis and broadened the range of efficiency hypotheses that can be formulated and tested. The production frontier approach to technical inefficiency measurement makes it possible to distinguish between shifts in technology from movements towards the best-practice frontier. By estimating the best-practice production function (an unobservable function) this approach calculates technical efficiency as the distance between the frontier and the observed output. The advantage of frontier analysis is that 
it provides an overall, objectively determined, numerical efficiency value and ranking of individual firms that is not otherwise available. The stochastic frontier approach allows observations to depart from the frontier due to both random error and inefficiency.

This paper adopts the model specification of Battese and Coelli (1992) who proposed a stochastic frontier production function for (unbalanced) panel data with firm effects that can vary systematically over time and are assumed to be distributed as truncated normal random variables. Thus the model is

$$
Y_{i t}=X_{i t} \beta+\left(V_{i t}-U_{i t}\right) \quad i=1,2, \ldots \ldots, \quad t=1,2, \ldots \ldots T
$$

where, $Y_{i t}$ is the logarithm of the production of the $i$-th industry in the $t$-th time period. $X_{i t}$ is a vector of input quantities of the $i$-th industry in the $t$-th time period and $\beta$ is a vector of unknown parameters. The error term comprises two separate parts. $V_{i t}$ are random variables assumed to be identically and independently distributed (iid) $N\left(0, \sigma_{v}{ }^{2}\right)$ and independent from $U_{i t}$. $U_{i t}$ captures technical inefficiency in production. $U_{i t}$ is defined by Battese and Coelli (1992) as:

$$
U_{i t}=U_{i}\{\exp [-\eta(t-T)]\}
$$

where $U_{i} \quad i=1,2, \ldots \ldots . N$ are assumed to be firm-specific non-negative random variables independently distributed as non-negative truncations at zero of the distribution $N\left(\mu, \sigma_{u}{ }^{2}\right) . \eta$ is an unknown parameter to be estimated, which determines whether inefficiencies are time-varying or time invariant.

In this model, the technical inefficiency effect for the $i$-th industry in the $t$-th time period, $U_{i t}$ is defined to be the product of an exponential function of time, $\exp [-\eta(t-T)]$, involving the unknown parameter, $\eta$, and the non-negative random variable $U_{i}$, which is the technical inefficiency effect for the $i$-th industry in 1999/2000, the last year of our data set. If $\eta$ is positive, then $-\eta(t-T) \equiv \eta(T-t)$ is positive for $t<T$ and so $\exp [-\eta(t-T)]>1$, which implies that the technical inefficiencies of industries decline over time. However, if $\eta$ is 
negative, then $-\eta(t-T)<0$ and thus technical inefficiencies increase over time.

The primary advantage of a stochastic frontier production is that it enables one to estimate $U_{i}$ and therefore to estimate industry specific technical efficiencies. The measure of technical efficiency is equivalent to the ratio of the production of the $i$-th industry in the $t$-th time period to the corresponding production value if the industry effect $U_{i}$ is zero.

Given the specifications of the stochastic frontier production function, defined by equation (1), the technical efficiency of the $i$-th industry in the $t$-th time period is defined by:

$$
T E_{i t}=\left(X_{i t} \beta-U_{i t}\right) /\left(X_{i t} \beta\right)
$$

where $U_{i t}$ and $X_{i t} \beta$ are defined by the specifications of the model in equation (1).

The technical efficiencies are predicted using the conditional expectation of the function $U_{i t}$ given the composed error term of the stochastic frontier (c.f. Battese and Coelli (1995)). On the basis of panel data, if the production frontier being estimated is Cobb-Douglas, like equation (1), it can be expressed in the following form:

$$
Y_{i t}=A L_{i t}^{\beta_{L}} K_{i t}^{\beta_{K}} e^{V_{i t}} e^{-U_{i t}}
$$

where $V_{i t}$ follows $N\left(0, \sigma_{v}{ }^{2}\right)$ and $U_{i t}$ follows a half or truncated normal distribution at zero. Taking natural $\log$ on both sides of equation (4), the following equation is obtained:

$$
\ln Y_{i t}=\ln A+\beta_{L} \ln L_{i t}+\beta_{K} \ln K_{i t}+\left(V_{i t}-U_{i t}\right)
$$

the subscripts, $i$ and $t$ represents $i$-th industry $(i=1,2,3,4)$ and $t$-th year of observation $(t=1,2,3, \ldots \ldots \ldots . .16)$, respectively. The one-sided distribution of $U_{i t}$ guarantees inefficiency to be positive only.

Given the specifications of the stochastic frontier production function, defined by equation (1), the null hypothesis, that technical inefficiency is not present in the model, is expressed by $H_{o}: \gamma=0$, where $\gamma$ is the variance ratio, explaining the total variation in output from the frontier level of output attributed to technical efficiencies and defined by 
$\gamma=\frac{\sigma_{u}{ }^{2}}{{\sigma_{v}}^{2}+\sigma_{u}{ }^{2}}$. This is done with the calculation of the maximum likelihood estimates for the parameters of the stochastic frontier model by using the computer program FRONTIER Version 4.1 (Coelli 1996). The parameter $\gamma$ must lie between 0 and 1. If the null hypothesis is accepted, this would indicate that $\sigma_{u}{ }^{2}$ is zero and hence that the $U_{i t}$ term should be removed from the model, leaving a specification with parameters that can be consistently estimated using ordinary least squares.

Further, the null hypothesis that the technical inefficiency effects are time invariant and that they have half-normal distribution are defined by $H_{o}: \eta=0$ and $H_{o}: \mu=0$ respectively. These hypotheses are tested using the generalized likelihood ratio test and the generalized likelihood ratio statistic, $\lambda$ is defined by $\lambda=-2 \ln \left[L\left(H_{o}\right) / L\left(H_{1}\right)\right]$, where $H_{o}$ and $H_{1}$ are the null and alternative hypotheses involved. If the null hypothesis, $H_{o}$, is true, then $\lambda$ is asymptotically distributed as a Chi-square (or mixed Chisquare) random variable. If the null hypothesis involves $\gamma=0$, then $\lambda$ has mixed Chi-square distribution (see Coelli, 1995, 1996) because $\gamma=0$ is a value on the boundary of the parameter space for $\gamma$.

\section{Data sources and variables construction}

\section{Data description}

Data for the selected group of industries have been drawn from the Census of Manufacturing Industries (CMI), conducted by the Bangladesh Bureau of Statistics (BBS) every year. Our area study covers selected 3-digit census factories, under the registered manufacturing sectors of Bangladesh over the reference period $1981 / 1982$ to $1999 / 2000$. As data for three years, viz., 1994/1995, 1996/1997, and 1998/1999 were not published, data for the remaining 16 years have been considered for our present study. The estimates at constant prices $(1981 / 1982=100)$ are derived.

The study focuses on a selected group of industries of the Bangladesh registered manufacturing sector. The selected group of industries are food manufacturing industries, beverage industries and tobacco industries under group one; textile manufacturing industries and apparel under group two; leather and its products, footwear and rubber products under group three; and non-metallic mineral products, fabricated metal 
products, electrical and non-electrical machinery under group four. The industries are grouped based on their nature.

The food manufacturing sector, presented in group one, plays an important role in the economy being necessary goods that are needed for daily life. Group two consists of textile manufacturing industries and apparel from which Bangladesh earns a major part of its foreign currency. About $75 \%$ of the total exports of Bangladesh came from this group. About 10 million people depend on the textile industries directly and indirectly for earning their livelihood. Every year Bangladesh earns about 6,500 million US dollars by exporting textile products. Leather and its products are another important sector for earning foreign currency.

\section{Variable construction}

Value added (Y): Gross value added figures are used in this study to represent value added and is equal to gross output minus industrial cost. Industrial costs include the cost of raw materials, fuel and electricity. We use value added instead of net value added to avoid the arbitrariness involved in depreciation estimates. To obtain the gross value added series in 'constant prices', the yearly current values were deflated by the industry price index of the relevant year.

Capital (K): Capital is one of the essential inputs in measuring productivity. Gross fixed assets are used in this study as capital inputs and these are the book values of land, buildings, machinery, tools, transport and office equipment, etc. The gross values of fixed assets have been weighted by the base year rates of return to get the measure of capital input. The rate of return is the ratio of non-wage value added to fixed assets as used here. The weighted capital input was then deflated by the capital goods price index that stands as a proxy of the whole machinery price index.

Labor $(\mathbf{L})$ : The number of employees directly or indirectly in production is used in this study as a labor input. It covers all workers including administrative, technical, clerical, sales and purchase staff. Thus all production and non-production workers except temporary daily casuals and unpaid workers are included in the analysis. In brief, they include production workers, salaried employees, and working proprietors. The best measure of labor input is the number of hours worked. As no such data are available for any industry, employment figures were taken as the second measure and were weighted by the base year wage rates to obtain measures of labor input. 


\section{Empirical Results}

\section{Estimation}

The maximum-likelihood estimates of the parameters in the CobbDouglas stochastic frontier production function were obtained by using the FRONTIER 4.1 program (Coelli, 1996). Tables 1 and 2 show the estimation results of the Cobb-Douglas production function on the basis of the stochastic frontier model by the method of maximum-likelihood estimation. The ordinary least square estimates of the parameters are used as initial values (to estimate) for the maximum-likelihood estimates of the parameters. The adjusted R-squared for the ordinary least square estimates is 0.78 , which indicates that 78 percent total variation of the output is explained by the input variables.

The maximum-likelihood estimate of the parameter with time-varying inefficiency effects for labor input is 0.0006 and -0.0268 for the truncated normal distribution and half-normal distribution respectively presented in Table-1, which indicates that they are insignificant. Bangladesh is one of the most densely populated countries and it has a labor surplus economy and so labor has a low output elasticity (see Coelli et. a1., 2003). The parameter estimate for capital input is significantly different from zero at the 1 percent level of significance for both the distributions. Again the elasticities of labor $\left(\beta_{L}\right)$ and capital $\left(\beta_{K}\right)$ respectively, indicate the values of 0.0006 and 0.2865 . Like the previous results in panel analysis, the stochastic frontier production function also shows greater elasticity for capital than for labor. However, economies of scale show variable returns to scale as 0.2871 in the stochastic frontier production function. Here it is not important to show increasing returns to scale or decreasing returns to scale, because we do not have an inference on the estimation of efficiency in the production function by the stochastic frontier model. In addition, inefficiency of the production function is calculated by the error term. In the truncated and half-normal distributions, the ratio of industry specific variability to total variability, $\gamma$, is positive and significant at the 1 percent level, implying that industry specific technical efficiency is important in explaining the total variability of output produced. However, the $\gamma$-estimate associated with the variance of the technical inefficiency effects is relatively small. The estimates for the parameters for the time-varying inefficiency model (1), presented in Table-1, indicate that the technical efficiency effects tend to decline over time since the estimate for the $\eta$ parameter is positive (i.e. $\hat{\eta}=0.0255$ ). Also the parameter $\mu$ is positive indicating that the distribution of the inefficiency effects is not more concentrated about zero than that of the half-normal distribution. 


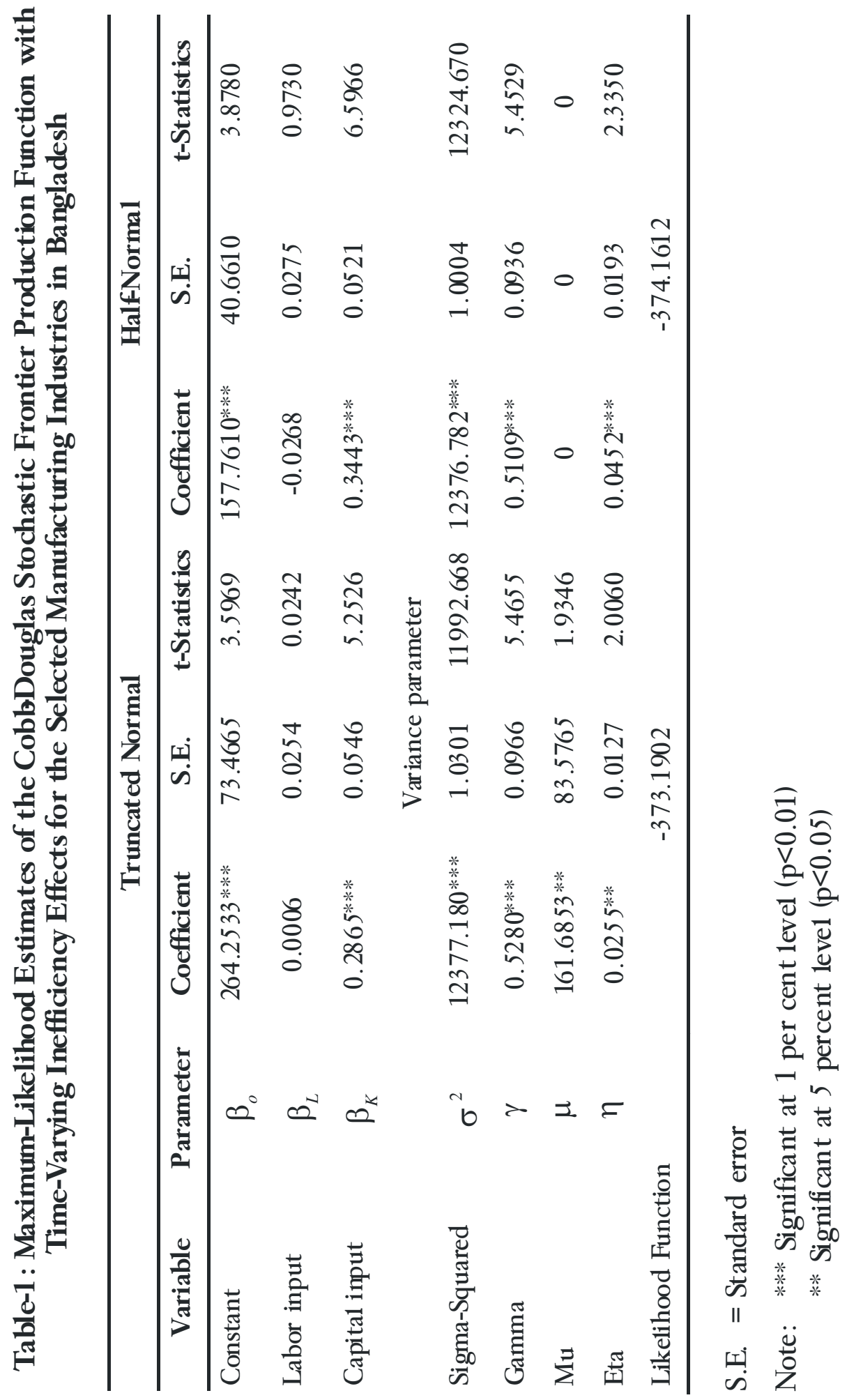







On the other hand, in Table-2, the maximum-likelihood estimates of the parameter (with time-invarying inefficiency effects) for the labor input, are negative and insignificant for both the truncated and the halfnormal distributions, while the coefficient of capital input values are positive and highly significant. In the case of both the truncated and halfnormal distributions, the values of $\gamma$ are positive and are highly significant demonstration that technical inefficiency exists in the selected manufacturing industries of Bangladesh. However, the $\gamma$-estimate associated with the variance of the technical inefficiency effects is relatively small. The $\eta$ parameter is restricted to zero in the model with time-invarying inefficiency effects.

\section{Tests}

The results of formal tests of various null hypotheses were obtained using the likelihood ratio (L-R) statistic and are presented in Table-3. These are obtained by using the values of log-likelihood functions for the selected manufacturing industries and the stochastic frontier production function. The first null hypothesis $H_{o}: \gamma=0$, which specifies that there are no technical inefficiency effects in the model, is rejected by the data. So the average response function is not an adequate representation of the data. This implies that the technical inefficiency effects associated with manufacturing industries in Bangladesh are significant. The technical inefficiency effects having a half-normal distribution, is tested by the null hypotheses $H_{o}: \mu=0$. In our study this hypothesis is accepted which indicates that the half normal distribution is preferable to the truncated normal (at zero) distribution for the technical inefficiency effect. The hypothesis $H_{o}: \eta=0$ is rejected, indicating that the technical inefficiency effect varies significantly over time. 
Table-3: Generalized Likelihood-Ratio Tests of Hypotheses for Parameters of the Stochastic Frontier Production Function for the selected Manufacturing Industries in Bangladesh

\begin{tabular}{lcccc}
\hline $\begin{array}{c}\text { Null } \\
\text { Hypothesis }\end{array}$ & $\begin{array}{c}\text { Log-Likelihood } \\
\text { Function }\end{array}$ & $\begin{array}{c}\text { Test Statistic } \\
\lambda\end{array}$ & $\begin{array}{c}\text { Critical } \\
\text { Value }\end{array}$ & Decision \\
\hline$H_{o}: \gamma=0$ & -380.1052 & 13.8300 & 7.05 & Reject $H_{o}$ \\
$H_{o}: \eta=\mu=0$ & -376.0553 & 5.7302 & 5.99 & Accept $H_{o}$ \\
$H_{o}: \mu=0$ & -374.1612 & 1.942 & 3.84 & Accept $H_{o}$ \\
$H_{o}: \eta=0$ & -375.5045 & 4.6286 & 3.84 & Reject $H_{o}$ \\
\hline
\end{tabular}

\section{Technical Efficiency}

The estimates of technical efficiency for the different groups of industries, obtained by using the FRONTIER 4.1 program (Coelli, 1996), are presented in Table-4. The mean efficiency for the truncated normal distribution is found to be 0.4022 and the range is 0.0033 to 0.6979 whereas for the half-normal distribution, mean efficiency is 0.5557 ranging from 0.0173 to 0.8951 . This implies that $40.22 \%$ and $55.57 \%$ of potential output is being realized in the selected manufacturing industries of Bangladesh according to the truncated (at zero) normal distribution and half-normal distribution respectively. There is a wide variation in the technical efficiencies of selected manufacturing industries. The mean technical efficiency of both distributional forms implies that the selected manufacturing industries are not achieving 100 percent of potential output. The hypothesis test confirmed the existence of inefficiency. The estimated industry-specific technical efficiency measures for each year are presented in Table-4 while Figure 1 shows the relevant probability histogram. The mean efficiency for the truncated normal distribution indicates the range of values between 0.2812 and 0.5096 while for the half-normal distribution the mean efficiency varies from 0.3898 to 0.6901 . The technical efficiency measures increased in both distributions in each group of industries. In other words, the overall average levels of efficiency have increased over the period 1981/82 - 1999/2000. Nevertheless, individual technical efficiency estimates exhibit considerable variation. The half-normal distribution gives higher technical efficiency estimates than the truncated normal distribution. Group one was the most efficient group relatively whereas group three is the least efficient. Although the growth rate of technical efficiency for group three is found to be the greatest, its technical efficiency remains the lowest. 


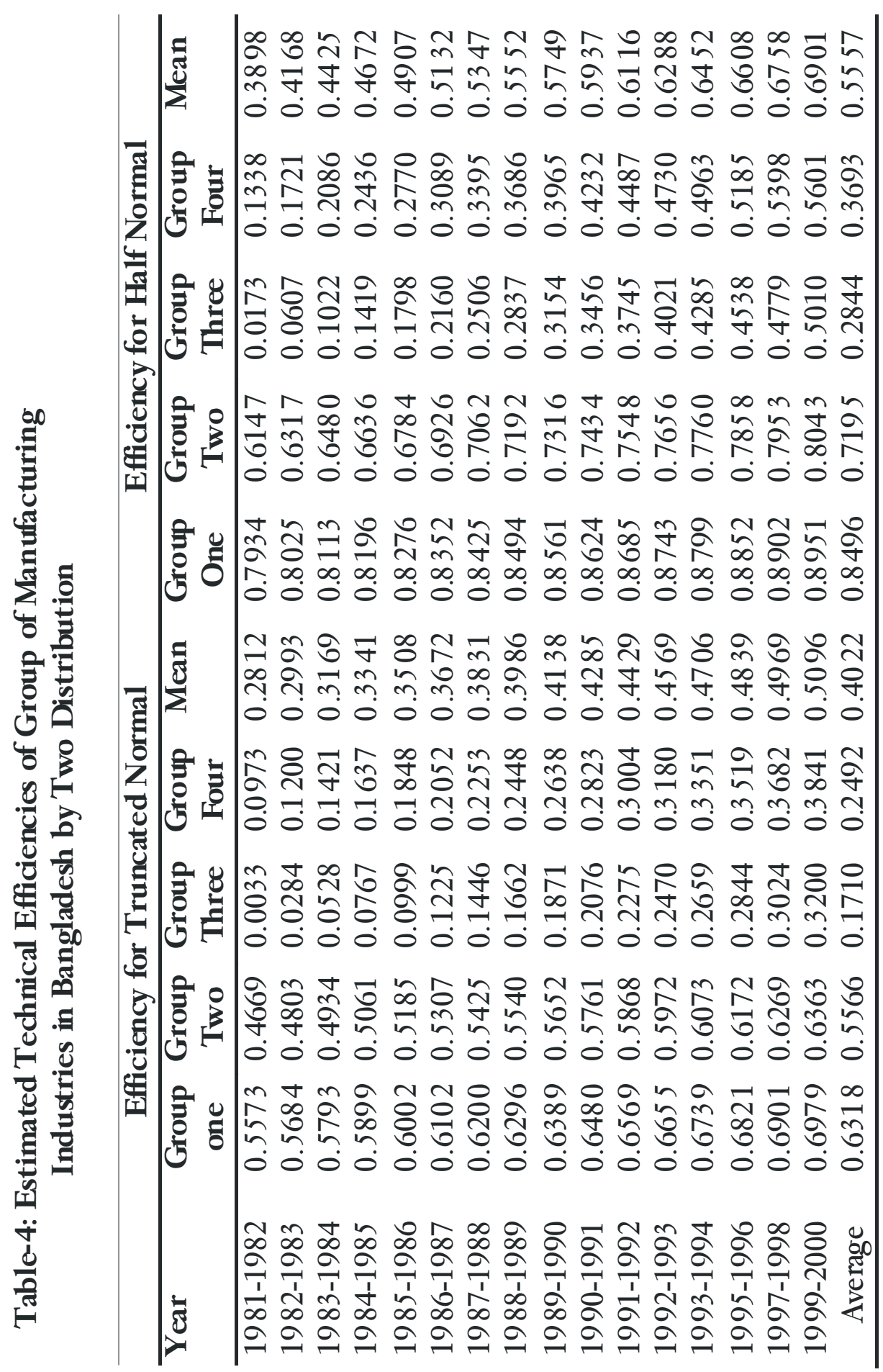




\section{Conclusion}

In this study, we have analyzed the stochastic frontier production function using panel data in selected manufacturing industries in Bangladesh. We have observed that the estimated values of the time-varying inefficiency parameter, $\eta$, are positive for both the truncated and the half normal distribution. These indicate that technical inefficiency has declined over the reference period. Tests for different null hypotheses involved in the stochastic frontier production function showed that the technical inefficiency effects for the selected manufacturing industries in Bangladesh are significant. It has been found that the mean efficiencies according to the truncated and the half normal distributions are 0.4022 and 0.5557 respectively. Here it should be noted that although the growth in technical efficiency was statistically significant over time as tested by the null hypothesis, the rate of increase in technical efficiency has been very slow over time in Bangladesh. 


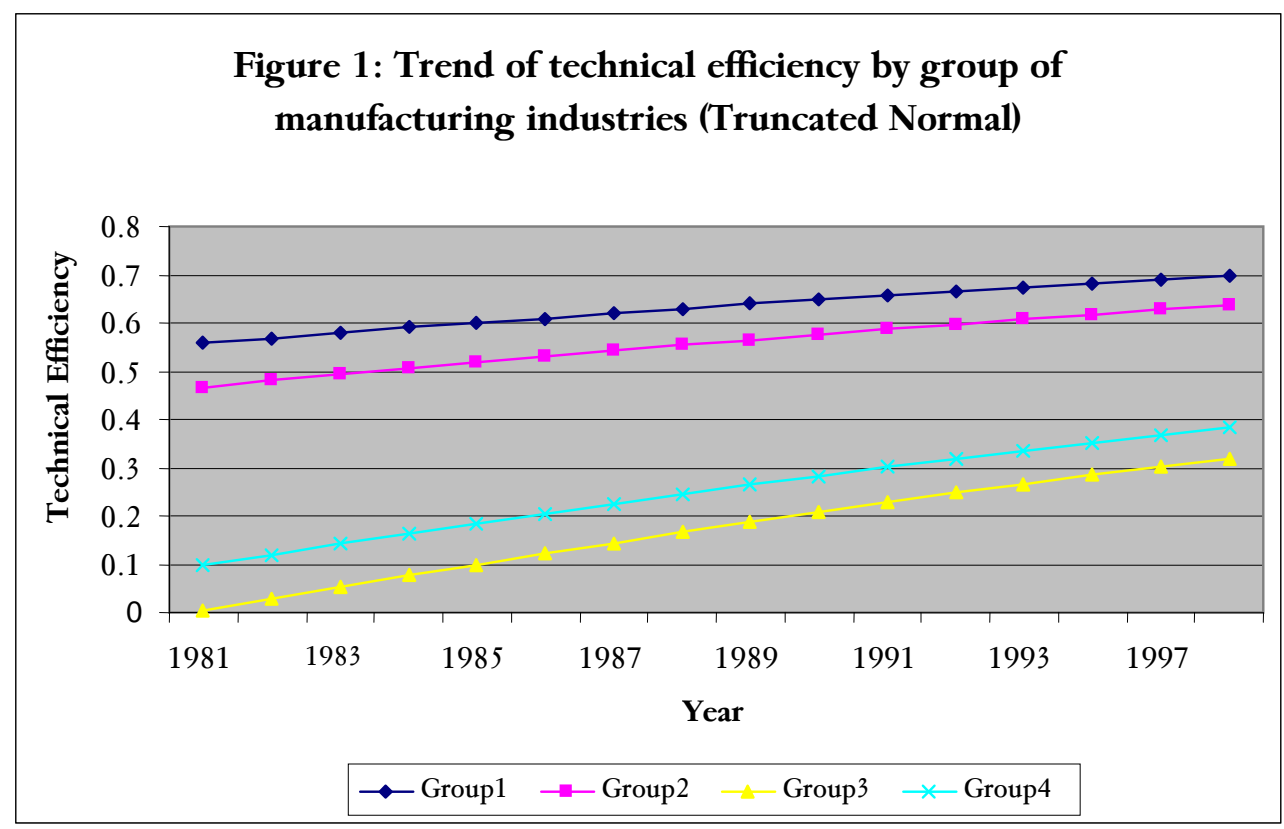

Figure 2: Trend of technical efficiency by group of manufacturing industry (Half Normal)

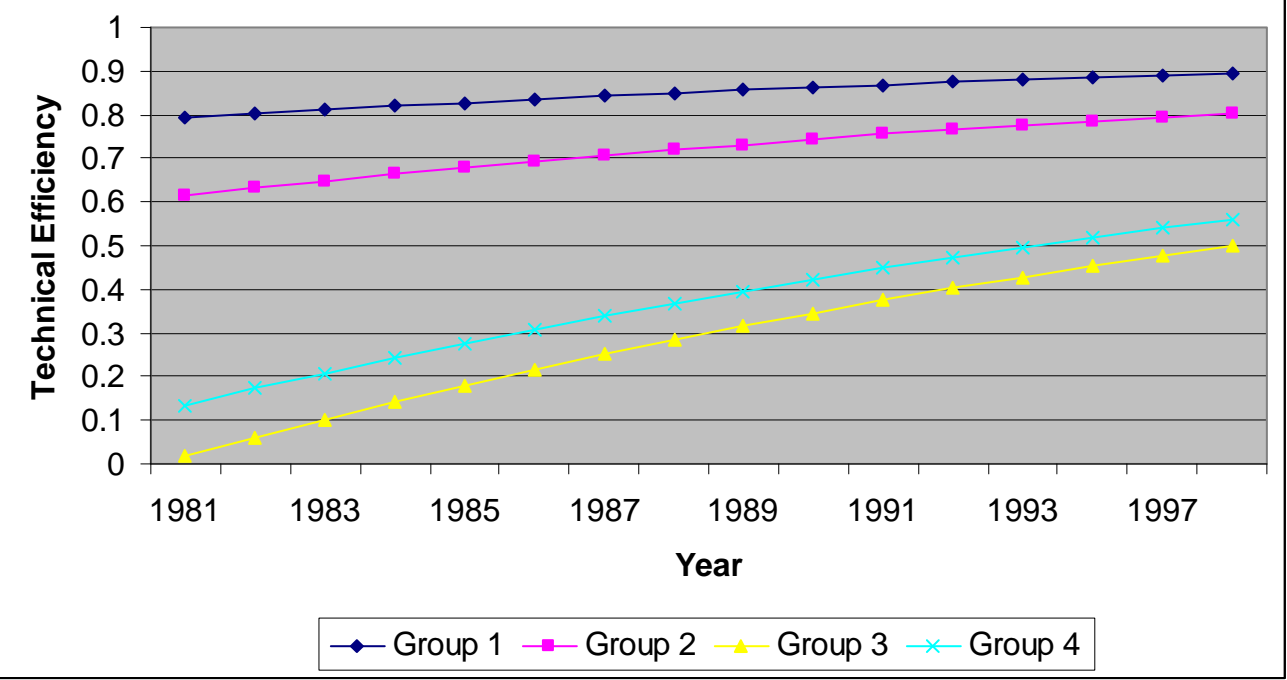




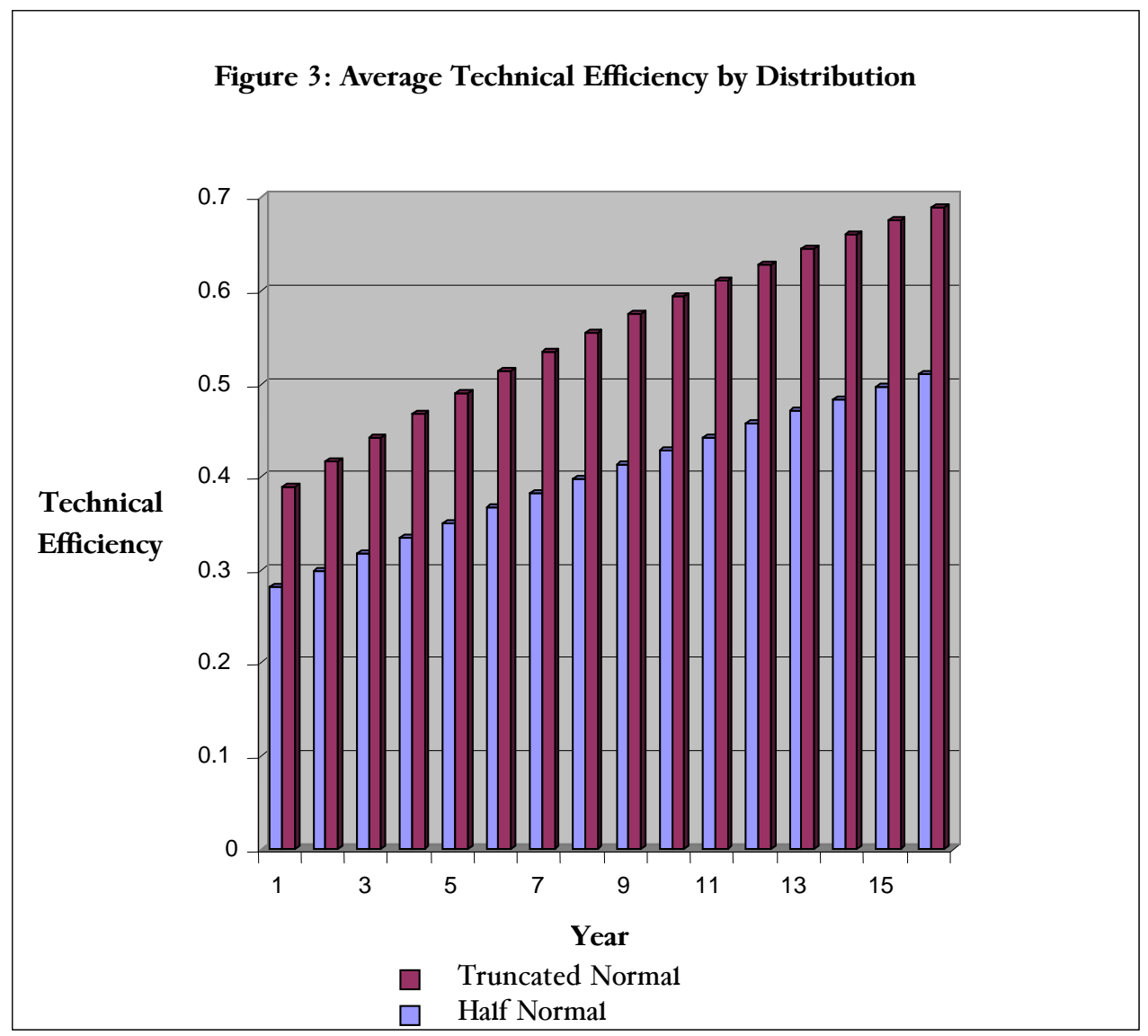




\section{References}

Ahmed A., and R. Sampath, 1992, 'Effects of Irrigation-induced Technological Change in Bangladesh Rice Production', American Journal of Agricultural Economics, 74: 144-157.

Aigner, D.J., Love11, C.A.K. and P. Schmidt, 1977, 'Formulation and Estimation of Stochastic Frontier Production Function Models', Journal of Econometrics, 6: 21-37.

Ajibefun, I.A., Battese G.E. and R. Kada, 1996, 'Technical Efficiency and Technological Change in the Japanese Rice Industry: A Stochastic Frontier Analysis', Centre for Efficiency and Productivity Analysis Working Papers, University of New England, Australia.

Battese, G.E. and G.S. Corra, 1977, 'Estimation of a Production Frontier Mode1: With Application to the Pastoral Zone of Eastern Australia', Australian Journal of Agricultural Economics, 21: 169-179.

Battese, G.E. and T.J. Coelli, 1992, 'Frontier Production Functions, Technical Efficiency and Panel Data: With Application to Paddy Farmers in India', Journal of Productivity Analysis, 3: 153-169.

Battese, G.E. and T.J. Coelli, 1995, 'A Model for Technical Inefficiency Effects in a Stochastic Frontier Production Function for Panel Data', Empirical Economics, 20: 325-332.

Battese, G.E., S.J. Malik and M.A. Gill, 1996, 'An Investigation of Technical Inefficiencies of Production of Wheat Farmers in Four Districts of Pakistan', Journal of Agricultural Economics, 47: 37-49.

Battese, G.E., S.J. Malik and S. Broca, 1993, 'Production Functions for Wheat Farmers in Selected Districts of Pakistan: An Application of Stochastic Frontier Production Function with Time-varying Inefficiency Effects', Pakistan Development Review, 32: 233-268.

Coelli, T., Sanjidur Rahman and Colin Thirtle, 2003, 'A Stochastic Frontier Approach to Total Factor Productivity Measurement in Bangladesh Crop Agriculture, 1961-92', Journal of International Development, 15: 321-333.

Coelli, T.J., 1995, 'Estimators and Hypotheses Tests for a Stochastic: A Monte Carlo Analysis', Journal of Productivity Analysis, 6, 247-268. 
Coelli, T.J., 1996, 'A Guide to FRONTIER Version 4.1: A Computer Program for Stochastic Frontier Production and Cost Function Estimation', CEPA Working Papers, No. 7/96, ISBN 186389 4950, Centre for Efficiency and Productivity Analysis, School of Economics, University of New England, Armidale, 33.

Cornwe11, C., P. Schmidt and R.C Sickles, 1990, "Production Frontier with Cross-sectional and Time-series Variation in Efficiency Levels", Journal of Econometrics, 46: 185-200.

D. S. P. Rao and T. J. Coelli, 1998, 'A Cross Country Analysis of GDP Growth Catch-up and Convergence in Productivity and Inequality', CEPA Working Papers, 5/98, Australia.

Debru, G., 1951, 'The Coefficient of Resource Utilization', Econometrica, 19: 273-292.

Farre11, M.J., 1957, 'The Measurement of Productive Efficiency', Journal of the Royal Statistical Society, Series A, 120: 253-290.

Greene, W.H., 1993, 'The Econometric Approach to Efficiency Analysis', in Fried, H. O., C. A. K. Lovell and S.S. Schmidt (Eds.), The Measurement of Productive Efficiency: Techniques and Applications, Oxford University Press, New York, 68-119.

Jafrullah, M., 1996, 'Technical Efficiencies of Some Manufacturing Industries of Bangladesh: An Application of the Stochastic Frontier Production Function Approach', The Bangladesh Development Studies, Vol. XXIV, Nos. $1 \& 2$.

Koopmans, T.C., 1951, 'An Analysis of Production as an Efficient Combination of Activities', in T.C. Koopmans, Ed., Activity Analysis of Production and Allocation, Cowles Commission for Research in Economics, Monograph No.13, Wiley, New York.

Kumbhakar, S.C., 1990, 'Production Frontiers, Panel Data and Time-varying Technical Efficiency', Journal of Econometrics, 46: 201-211.

Kumbhakar, S.C., S. Ghosh and J.T. McGuckin, 1991, "A Generalized Production Frontier Approach for Estimating Determinants of Inefficiency in U.S. Dairy Farms", Journal of Business and Economic Statistics, 9: 279-286. 
Meeusen, W., and J. van den Broeck, 1977, 'Efficiency Estimation from Cobb-Douglas Production Function with Composed Error', International Economic Review, 18: 435-444.

Pitt, M.M. and L-F. Lee, 1981, 'Measurement and Sources of Technical Inefficiency in the Indonesian Weaving Industry', Journal of Development Economics 9: 43-64.

Taymaz, E. and Saatci, G., 1997, 'Technical Change and Efficiency in Turkish Manufacturing Industries', Journal of Productivity Analysis, 8: 461-475.

Tzouvelekas, V., K. Giannakas, P. Midmore and K. Mattas, 1991, 'Decomposition of Olive Oil Production Growth into Productivity and Size Effects: A Frontier Production Function Approach', Cahiers d'economic et Sociologic rurales, No.51. 